\title{
Intermetallic Reaction of Indium and Silver in an Electroplating Process
}

\author{
PIN J. WANG, ${ }^{1,2}$ JONG S. KIM,${ }^{1}$ and CHIN C. LEE ${ }^{1}$ \\ 1.-Electrical Engineering and Computer Science, Materials and Manufacturing Technology, \\ University of California, Irvine, CA 92697-2660, USA. 2.—e-mail: pinjanw@uci.edu
}

The reaction of indium (In) and silver (Ag) during the electroplating process of indium over a thick silver layer was investigated. It was found that the plated In atoms react with $\mathrm{Ag}$ to form $\mathrm{AgIn}_{2}$ intermetallic compounds at room temperature. Indium is commonly used in the electronics industry to bond delicate devices due to its low yield strength and low melting temperature. In this study, copper $(\mathrm{Cu})$ substrates were electroplated with a 60- $\mu$ m-thick Ag layer, followed by electroplating an In layer with a thickness of $5 \mu \mathrm{m}$ or $10 \mu \mathrm{m}$, at room temperature. To investigate the chemical reaction between In and Ag, the microstructure and composition on the surface and the cross section of samples were observed by scanning electron microscopy (SEM) with energydispersive $\mathrm{x}$-ray spectroscopy (EDX). The x-ray diffraction method (XRD) was also employed for phase identification. It was clear that indium atoms reacted with underlying $\mathrm{Ag}$ to form $\mathrm{AgIn}{ }_{2}$ during the plating process. After the sample was stored at room temperature in air for 1 day, $\mathrm{AgIn}_{2}$ grew to $5 \mu \mathrm{m}$ in thickness. With longer storage time, $\mathrm{AgIn}{ }_{2}$ continued to grow until all indium atoms were consumed. The indium layer, thus, disappeared and could barely be detected by XRD.

Key words: Indium, silver, intermetallic reaction, $\mathrm{AgIn}_{2}$, electroplating

\section{INTRODUCTION}

Besides tin, indium is an important element for soft solder formulations. Indium has a relatively low yield strength and low melting temperature. Its yield strength is $310 \mathrm{psi}$, only one-tenth that of Sn-3.5Ag eutectic solders. ${ }^{1}$ Its melting temperature of $156^{\circ} \mathrm{C}$ is $60^{\circ} \mathrm{C}$ lower than that of $\mathrm{Sn}-3.5 \mathrm{Ag}$ eutectic solders. These properties make indium attractive for bonding applications that need low process temperature and high ductility; for example, indium has been used to bond the backside of large central processing unit (CPU) chips to $\mathrm{Cu}$ heat sinks.

Since indium is oxidized easily, nearly all bonding processes require the use of fluxes to achieve bonding. We have developed fluxless bonding processes involving In with In-Ag, In-Au, and In-Sn

Jong S. Kim now with Applied Materials.

(Received August 19, 2008; accepted May 12, 2009;

published online June 9, 2009) systems. ${ }^{2-5}$ In these fluxless processes, a thin outer $\mathrm{Ag}$ or Au capping layer is used in solder manufacturing to prevent indium oxidation. The multilayer solder structures can then be fabricated using vacuum deposition techniques or electroplating processes. Compared with the electroplating method, vacuum deposition techniques produce cleaner and more uniform metallic films. They also give better thickness control and oxidation prevention. However, it is more costly and difficult to produce layers thicker than $10 \mu \mathrm{m}$. The electroplating process has become popular in the manufacture of solder layers.

Although the In-Ag system has been used to assemble optoelectronic devices in the electronics industry, ${ }^{6,7}$ chemical reactions between the plated In layer and $\mathrm{Ag}$ layer have seldom been documented. The investigation of In-Ag reactions at room temperature can greatly help the electronics packaging community understand wetting and soldering actions of the soldering processes based on the In-Ag system. It would further facilitate fluxless bonding design and development. In recent process 
development of plating In over Ag, we discovered that In atoms react with the underlying $\mathrm{Ag}$ layer to form $\mathrm{AgIn} \mathrm{In}_{2}$ as soon as the In atoms are deposited over the Ag layer during the plating process. The $\mathrm{AgIn}$ layer grows with time until all indium atoms are consumed. Herein, the experimental design and procedures are presented, followed by experimental results and discussion. A short summary is then given.

\section{EXPERIMENTAL PROCEDURES}

First, we performed nucleation and microstructural studies of sequential electroplating of indium and silver on a copper substrate. In our design, we started by plating a thick Ag layer on $10 \mathrm{~mm} \times$ $12 \mathrm{~mm} \mathrm{Cu}$ substrates. The thick Ag layer over $\mathrm{Cu}$ was chosen to enhance substrate performance. Agcopper dual-layer substrates have higher electrical and thermal conductivities than pure $\mathrm{Cu}$ substrates. The thick Ag layer also functions as a stress buffer to release shear stress when semiconductor chips are bonded to the Ag layer on the $\mathrm{Cu}$ substrate. The $\mathrm{Cu}$ substrates used in this study are made of alloy 110 having $99.9 \%$ pure $\mathrm{Cu}$ with a one-side mirror finish. Figure 1 depicts the cross section of the sample prepared for studying intermetallic reactions during electroplating processes. $\mathrm{On}$ a $\mathrm{Cu}$ substrate, a thick $\mathrm{Ag}$ layer was electroplated, followed by indium plating. The $\mathrm{Ag}$ plating bath is a cyanide-free, mildly alkaline plating solution at $\mathrm{pH}$ 10.5. The plating process was performed by stirring. A plating area of $10 \mathrm{~mm} \times 12 \mathrm{~mm}$ was defined by stop-off lacquer to prevent deposition on the backside. The lacquer was removed after the plating. The current density and process temperature were $12 \mathrm{~mA} / \mathrm{cm}^{2}$ and room temperature, respectively. The $60-\mu \mathrm{m}$-thick Ag layer was plated on the $\mathrm{Cu}$ substrate in $180 \mathrm{~min}$. After the Ag plating, the sample was rinsed with deionized water, followed immediately by In plating in a sulfamate indium bath. Two groups of samples were produced, with In thickness of $5 \mu \mathrm{m}$ and $10 \mu \mathrm{m}$, respectively. In the plating setup, a pure (99.99\%) indium block was used as the anode, which also provided indium replenishment to replenish the more expensive bath concentrate. The indium plating bath is at $\mathrm{pH}$ of 1 to 3.5 and the plating process was performed by stirring. Operating temperature and current density were room temperature and $21.5 \mathrm{~mA} / \mathrm{cm}^{2}$, respectively.

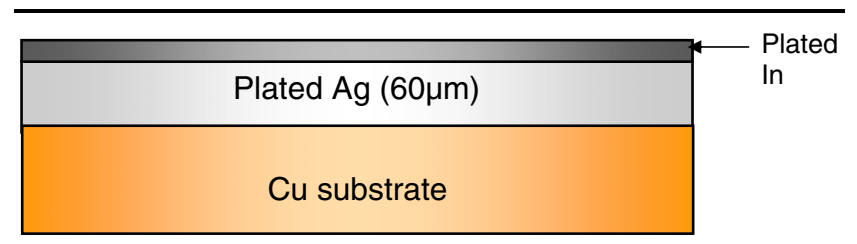

Fig. 1. The electroplated structure of $\mathrm{Cu} / \mathrm{Ag} / \mathrm{ln}$.
SEM with EDX was employed to analyze the chemical compositions on the cross section and on the surface of electroplated films. To identify phases of electroplated samples, the surface of the film rather than the cross section was scanned by x-ray diffractometer. XRD measurements were taken at several time points ranging from 1 day to 3 weeks after samples were made.

\section{EXPERIMENTAL RESULTS}

\section{$\mathbf{C u} / \mathbf{A g} / \mathbf{I n}$ Samples with 5- $\mu$ m Indium}

Figure 2 shows a cross-sectional SEM image of a $\mathrm{Cu} / \mathrm{Ag} / \mathrm{In}(5 \mu \mathrm{m})$ sample. The EDX analysis shows four distinct regions with different compositions. Based on the Ag-In phase diagram, ${ }^{8}$ the first region, with 85 at.\% to 95 at.\% In and 5 at.\% to 15 at.\% $\mathrm{Ag}$, is identified as an In-rich InAg alloy. Pure In was hardly detected. Below this region, 5- $\mu \mathrm{m}$-thick $\mathrm{AgIn}_{2}$ compounds having 65 at.\% to 70 at.\% In and 30 at.\% to 35 at.\% Ag were detected. The third region is a Ag-In alloy layer with 85 at.\% to 55 at.\% $\mathrm{Ag}$, where the $\mathrm{Ag}$ content increases towards the bottom. The fourth region is identified as pure Ag. From SEM/EDX results, it is clear that In atoms react with $\mathrm{Ag}$ to form $\mathrm{AgIn}{ }_{2}$ compounds during the plating process.

To confirm this reaction, the XRD method was applied. XRD measurements were taken after the sample was plated for 1 day and 3 weeks, respectively. Figure $3 a$ and $b$ show the resulting x-ray diffraction data. In Fig. 3a, several peaks associated with $\mathrm{AgIn}_{2}$ are observed, i.e., $\operatorname{AgIn}_{2}(112)$, $\mathrm{AgIn}_{2}(202)$, and $\mathrm{AgIn}_{2}(004)$. Some peaks resulting from pure indium are also detected, i.e., $\operatorname{In}(002)$ and In(202). The peaks at $32.98^{\circ}$ and $63.27^{\circ}$ are coincident peaks because the $\mathrm{AgIn}_{2}$ and In peaks coincide at these two angles. The $\mathrm{AgIn}_{2}$ peaks shown in Fig. 3a agree with the SEM/EDX result of In and Ag reacting to form $\mathrm{AgIn}_{2}$ at room temperature. On the other hand, the indium peaks in Fig. $3 \mathrm{a}$ indicate that pure indium still exists in the sample, likely near the surface. On the cross-sectional sample, the

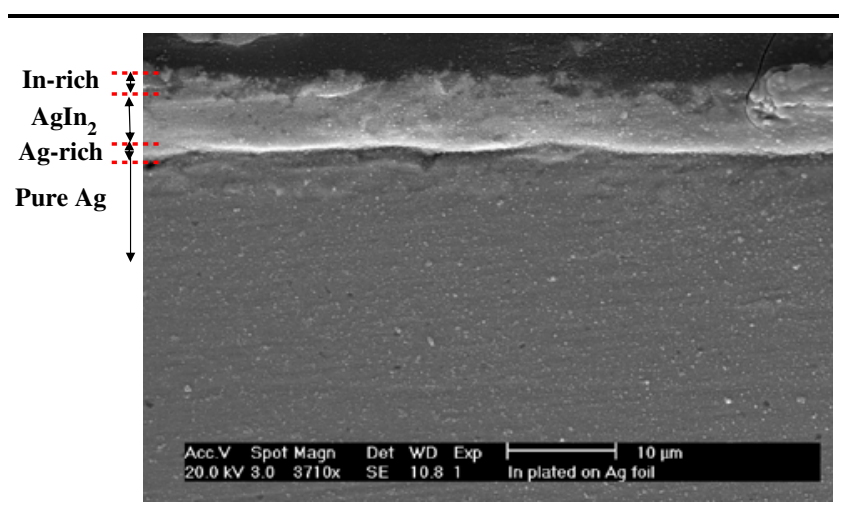

Fig. 2. SEM cross-section image of the $\mathrm{Cu} / \mathrm{Ag} / \mathrm{ln}(5 \mu \mathrm{m})$ structure; it consists of four distinct regions: In-rich, $\mathrm{AgIn} \mathrm{n}_{2}, \mathrm{Ag}$-rich, and pure Ag. 

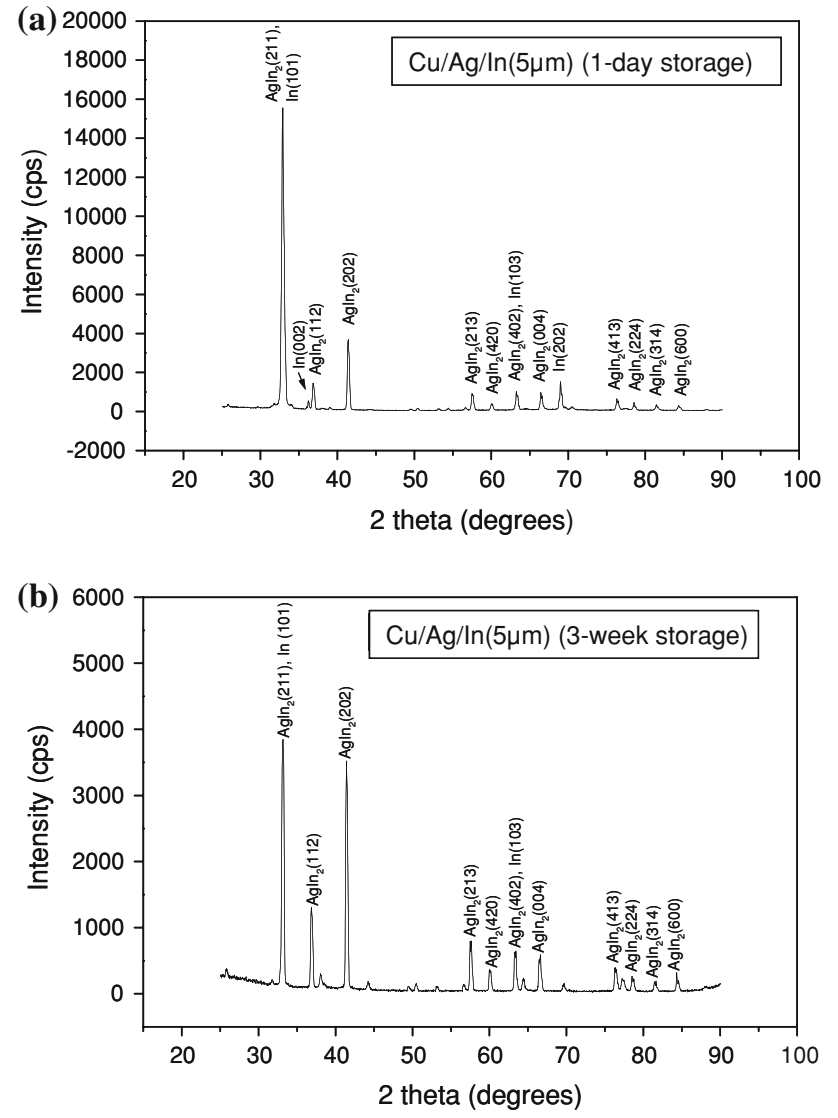

Fig. 3. XRD spectra from the $\mathrm{Cu} / \mathrm{Ag} / \ln (5 \mu \mathrm{m})$ sample: (a) 1 day and (b) 3 weeks after it is made.

pure indium region does not show up on the SEM image (Fig. 3). The reason is that indium is very ductile and soft. It is very difficult to preserve the cross section of a thin ductile surface layer on the sample during dicing and polishing operations.

The same sample was kept for 3 weeks and examined by the x-ray diffraction method again. The result is displayed in Fig. $3 \mathrm{~b}$. It is interesting to observe that the $\operatorname{In}(002)$ and $\operatorname{In}(202)$ peaks have disappeared. This indicates that In atoms continue to react with $\mathrm{Ag}$ atoms to form more $\mathrm{AgIn} \mathrm{In}_{2}$ during the 3 -week storage. In this manner, all In atoms were consumed after 3 weeks. The intensity of the coincident peak at $32.98^{\circ}$ became weaker relatively to all other AgIn $\mathrm{In}_{2}$ peaks. This particular peak could come from $\operatorname{In}(101)$ and $\operatorname{AgIn}_{2}(211)$. Its decrease after the 3-week storage implies that a significant portion of the intensity at $32.98^{\circ}$ measured right after plating (Fig. 3a) was derived from $\operatorname{In}(101)$.

\section{Cu/Ag/In Samples with 10- $\mu \mathrm{m}$ Indium}

After we discovered the AgIn 2 growth during the electroplating of the 5- $\mu \mathrm{m}$-thick In over Ag, samples of the Ag-copper dual-layer substrates plated with a $10-\mu \mathrm{m}$-thick In layer over Ag were produced to compare the compound formation reaction. The top surface of $\mathrm{Cu} / \mathrm{Ag} / \mathrm{In}$ sample was examined using SEM/EDX 1 day after the sample had been made. Top-view SEM images and the corresponding compositions at several spots are illustrated in Fig. 4 and Table I, respectively. It was seen that the surface exhibits pure In grains with an average size of $5 \mu \mathrm{m}$ after the 1-day storage. The same sample was kept for 12 days and observed under SEM/EDX

Table I. EDX Spectra from the Top View of the $\mathrm{Cu} / \mathrm{Ag} / \mathrm{In}(10 \mu \mathrm{m})$ Sample Shown in Fig. 4

\begin{tabular}{|c|c|c|}
\hline Spot & at. $\%$ & Composition \\
\hline $\mathrm{A}$ & $\operatorname{In}(98), \operatorname{Ag}(2)$ & Pure In \\
\hline $\mathrm{B}$ & $\operatorname{In}(100)$ & \\
\hline $\mathrm{C}$ & $\operatorname{In}(99), \operatorname{Ag}(1)$ & \\
\hline $\mathrm{D}$ & $\operatorname{In}(99), \operatorname{Ag}(1)$ & \\
\hline $\mathrm{E}$ & $\operatorname{In}(80), \operatorname{Ag}(20)$ & Ag-In alloy \\
\hline $\mathrm{F}$ & $\operatorname{In}(81), \operatorname{Ag}(19)$ & \\
\hline $\mathrm{G}$ & $\operatorname{In}(66), \operatorname{Ag}(34)$ & $\operatorname{AgIn}_{2}$ \\
\hline $\mathrm{H}$ & $\operatorname{In}(67), \operatorname{Ag}(33)$ & \\
\hline I & $\operatorname{In}(99), \operatorname{Ag}(1)$ & Pure In \\
\hline$J$ & $\operatorname{In}(98), \operatorname{Ag}(2)$ & \\
\hline
\end{tabular}

The compositions of spots A to D are from the sample stored for 1 day, and those of spots $\mathrm{E}$ to $\mathrm{J}$ are from the same sample but stored for 12 days.
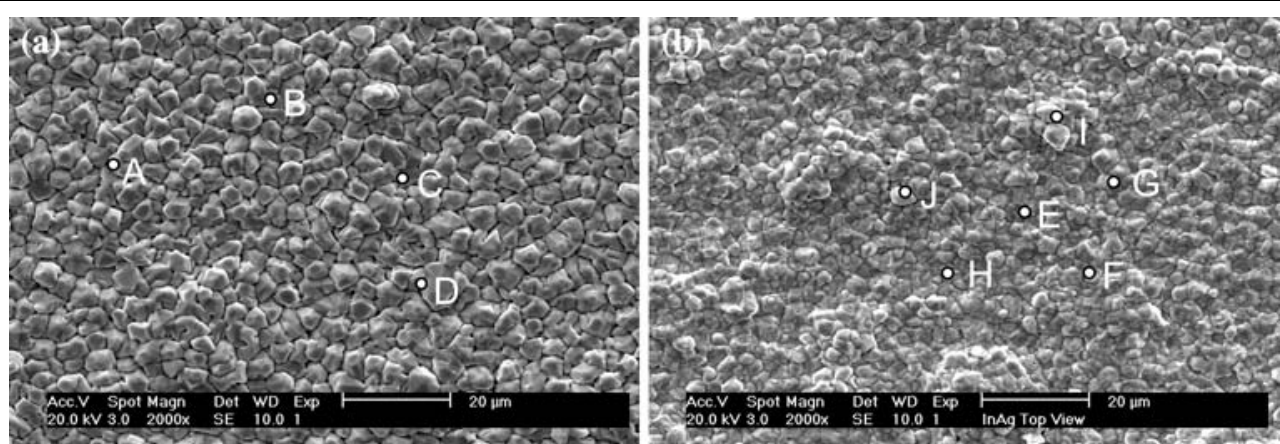

Fig. 4. SEM images of the top surface of the $\mathrm{Cu} / \mathrm{Ag} / \mathrm{In}(10 \mu \mathrm{m})$ sample: (a) 1 day and (b) 12 days after it is made. EDX data on spots $\mathrm{A}$ to $\mathrm{J}$ are given in Table I. 
again. During the 12-day storage at room temperature, some $\mathrm{Ag}$ atoms diffused to the surface. EDX data reveal three regions with different compositions. Spots E and F represent $\mathrm{AgIn}_{2}$ intermetallic compounds. Spots $\mathrm{G}$ and $\mathrm{H}$ are identified as Ag-In alloys with composition of 20 at.\% $\mathrm{Ag}$ and 80 at.\% In. Pure In is also detected, marked as spots I and J. Although these three regions have different compositions, their surface appearances in Fig. 4b are almost the same; this is because Ag and In atoms emit similar amounts of secondary electrons under SEM analysis. During 12-day storage, Ag and In atoms continued to interdiffuse and react. The average grain size shrunk to approximately $3 \mu \mathrm{m}$, and the grain boundaries became blurred (Fig. 4b). To understand the chemical reaction at the $\mathrm{Ag} / \mathrm{In}$ interface, the cross sections of $\mathrm{Cu} / \mathrm{Ag} / \mathrm{In}(10 \mu \mathrm{m})$ samples were also examined after storage for 1 day and 12 days, respectively, as illustrated in Fig. 5a, b. Three distinct layers, In, $\mathrm{AgIn}_{2}$, and $\mathrm{Ag}$, are indicated in Fig. 5a. The $\mathrm{AgIn}_{2}$ layer had grown to $5 \mu \mathrm{m}$ in thickness after 1-day storage, which is similar to the result for $\mathrm{Cu} / \mathrm{Ag} / \operatorname{In}(5 \mu \mathrm{m})$ samples exhibited in Fig. 2. After 12-day storage, the AgIn 2 layer grew to $12 \mu \mathrm{m}$, as shown in Fig. 5b. It is clear that, after an In layer is plated over a Ag layer, In atoms and $\mathrm{Ag}$ atom react to form $\mathrm{AgIn}_{2}$ immediately. Based on the reaction equation $\mathrm{Ag}+2 \mathrm{In} \rightarrow$ $\mathrm{AgIn}$, we calculated that it takes a $3.3-\mu \mathrm{m}$-thick $\mathrm{Ag}$ layer to react completely with a $10-\mu \mathrm{m}$-thick In layer to form $\mathrm{AgIn}_{2}$. The resulting $\mathrm{AgIn}_{2}$ thickness should be $13 \mu \mathrm{m}$ in theory. Here, a $12-\mu \mathrm{m}$-thick $\mathrm{AgIn}$ layer is observed.

To confirm the compound formation, the surface of a $\mathrm{Cu} / \mathrm{Ag} / \mathrm{In}(10 \mu \mathrm{m})$ sample was scanned by $\mathrm{x}$-ray diffractometer at four time points: 1 day, 6 days, 12 days, and 15 days after the sample had been plated. Figure 6 shows the x-ray diffraction patterns. After 1-day storage, shown as pattern (a) in Fig. 6, all peaks are associated with pure In. Peaks caused by $\mathrm{AgIn}$. alone do not exist. After 6-day storage, some $\mathrm{AgIn}$. peaks start to appear. With longer storage time, the intensity of $\mathrm{AgIn}_{2}$ peaks becomes stronger, and that of In peaks becomes gradually weaker. The $\mathrm{x}$-ray diffraction data confirm the results obtained from SEM/EDX; that is, the In layer reacts with the underlying $\mathrm{Ag}$ layer to form $\mathrm{AgIn}_{2}$ when a sample is stored at room temperature. The weight fraction of indium in the mixture on the sample surface can be estimated using the $\mathrm{x}$-ray diffraction data. The relation between diffraction intensity and concentration is given by the equation

$$
\begin{aligned}
& \frac{I_{\text {In in mixture }}}{I_{\text {In }}} \\
& =\frac{w_{\text {In }}\left(\mu_{\text {In }} / \rho_{\text {In }}\right)}{\left[w_{\text {In }}\left(\mu_{\text {In }} / \rho_{\text {In }}-\mu_{\mathrm{AgIn}_{2}} / \rho_{\mathrm{AgIn}_{2}}\right)+\mu_{\mathrm{AgIn}_{2}}+\rho_{\mathrm{AgIn}_{2}}\right]},
\end{aligned}
$$

where $I_{\text {In in mixture }}$ is the integrated intensity caused by an In phase in a mixture, $I_{\text {In }}$ is the integrated intensity caused by an In phase in a pure In phase, $w_{\text {In }}$ denotes the weight fraction of the In phase in the mixture, $\mu$ represents the linear absorption coefficient, and $\rho$ is the mass density. Based on the x-ray diffraction data sheet, $\mu_{\text {In }} / \rho_{\text {In }}=242.1 \mathrm{~cm}^{2} / \mathrm{gm}$ and $\mu_{\mathrm{AgIn}_{2}} / \rho_{\mathrm{AgIn}_{2}}=484.1 \mathrm{~cm}^{2} / \mathrm{gm}$ for $\mathrm{Cu} \mathrm{K}_{\alpha}$ radiation. 9,10 The cross-section SEM image at 1-day storage (Fig. 5a) shows that the In layer is still $8 \mu \mathrm{m}$ thick. It thus can be assumed that there are only In atoms on the surface after 1 day storage. Using the intensity of the $69.12^{\circ}$ peak after 1-day storage and the diffraction curve (Fig. 6b) after 6-day storage, the compositions of the sample surface after 6-day storage are calculated to be $67 \mathrm{wt} \%$ In and $33 \mathrm{wt} . \%$ $\mathrm{AgIn}_{2}$. At 12 days, the calculated surface compositions are 26 wt.\% In and 74 wt.\% $\mathrm{AgIn}_{2}$. At 15 days, the surface compositions are 4 wt.\% In and 96 wt.\% $\mathrm{AgIn}{ }_{2}$. At 15 days, the intensity of the In peak at $69.12^{\circ}$ is near the noise level. Thus, the surface composition estimate is not accurate at 15 days. The XRD analysis results clearly show that, with increased storage time, more and more $\mathrm{Ag}$ atoms appear on the surface and form $\mathrm{AgIn} \mathrm{In}_{2}$ compounds. At 15 days, more than 96 wt. $\% \mathrm{AgIn}_{2}$ was detected on the surface.
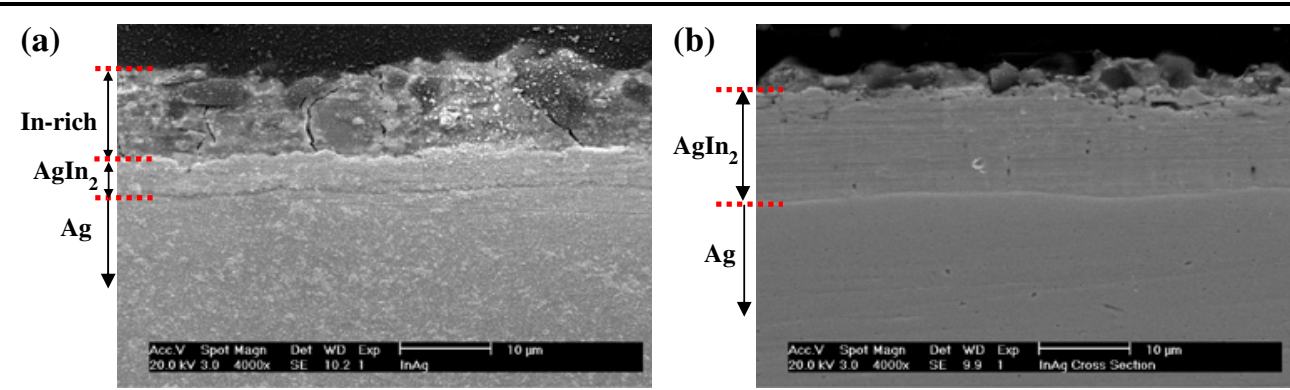

Fig. 5. SEM cross section images of the $\mathrm{Cu} / \mathrm{Ag} / \mathrm{In}(10 \mu \mathrm{m})$ structure. (a) Agln $\mathrm{I}_{2}$ layer has grown to $5 \mu \mathrm{m} 1$ day after the sample was made; (b) the $\mathrm{Agln}_{2}$ layer continues to grow to $15 \mu \mathrm{m} 12$ days after the sample was made. 


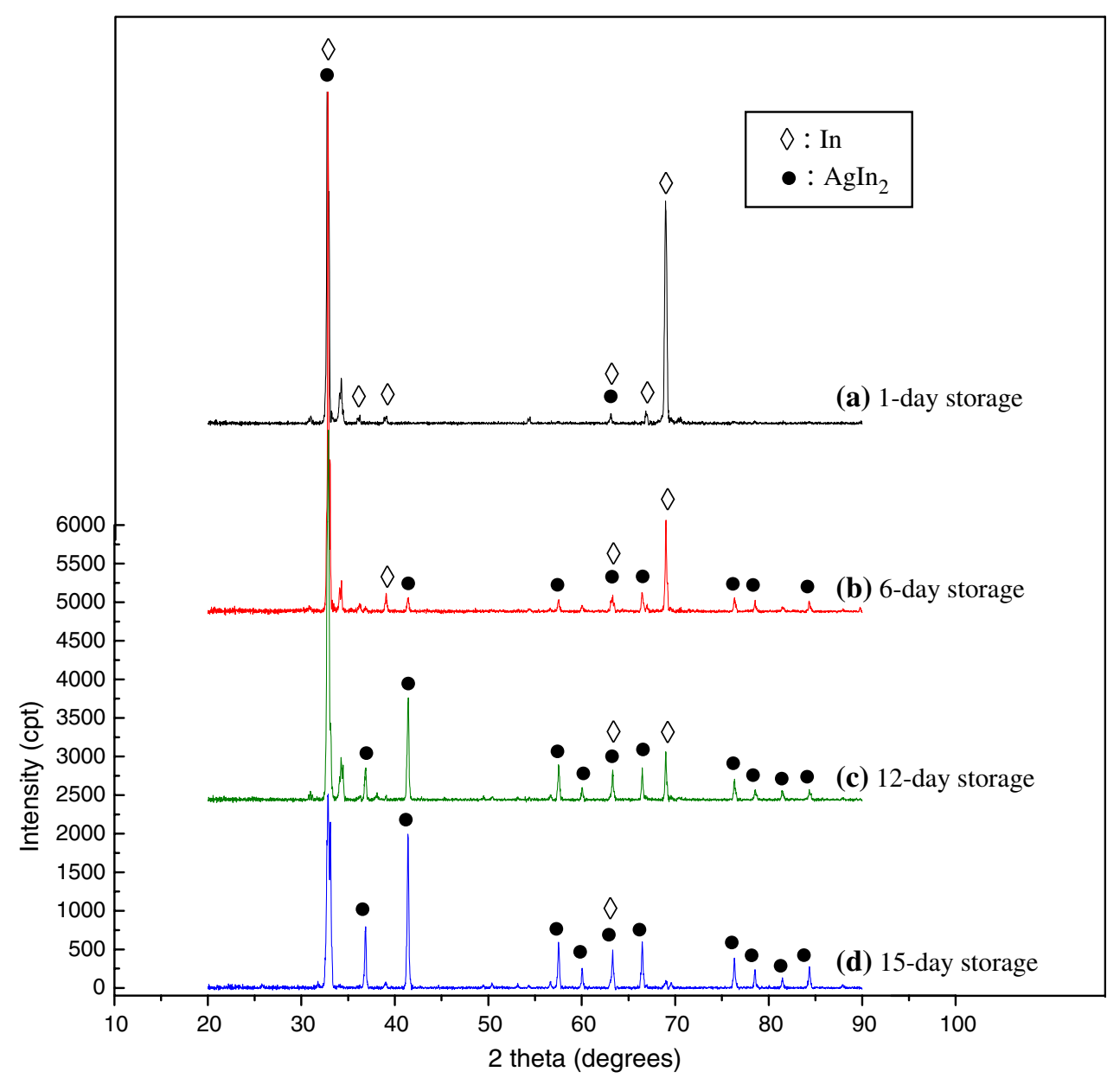

Fig. 6. X-ray diffraction pattern of the $\mathrm{Cu} / \mathrm{Ag} / \mathrm{In}(10 \mu \mathrm{m})$ sample detected at four different time points after the sample was plated and stored for: (a) 1 day, (b) 6 days, (c) 12 days, and (d) 15 days.

\section{DISCUSSION}

Based on the results reported by other research groups on interaction kinetics in Ag-In thin-film couples at room temperature, it is known that $\mathrm{AgIn}_{2}$ is formed as soon as In is deposited on $\mathrm{Ag}$ in a vacuum. ${ }^{11,12}$ The formation of $\mathrm{AgIn}_{2}$ phases is found to be a diffusion-controlled process. In their studies, film thicknesses are $15 \mathrm{~nm}$ to $150 \mathrm{~nm}$ for $\mathrm{Ag}$ and $30 \mathrm{~nm}$ to $170 \mathrm{~nm}$ for In. The total thickness of the couples is in the range of $180 \mathrm{~nm}$ to $200 \mathrm{~nm}$. It was found that, at room temperature, the diffusion rate of silver atoms in an indium layer and that of indium atoms in a silver layer are of the same order of magnitude, i.e., $10^{-14} \mathrm{~m}^{2} \mathrm{~s}^{-1}$. Silver atoms diffuse into indium via the interstitial mechanism, and indium atoms diffuse into silver through grain boundaries. As temperature increases, indium diffusion through silver grain boundaries becomes more dominant because the activation energy of the grain boundary diffusion $(0.34 \mathrm{eV})$ is smaller than that of the lattice diffusion $(0.55 \mathrm{eV})$. Once In and $\mathrm{Ag}$ atoms meet each other, they form $\mathrm{AgIn}_{2}$ compounds immediately as In and $\mathrm{AgIn}_{2}$ share the same crystal structure, i.e., the body-centered tetragonal structure.

Our experimental setup and parameters were quite different from others' research. The plated In layer was $5 \mu \mathrm{m}$ thick and the Ag layer was $60 \mu \mathrm{m}$ thick. The thickness range was larger by a factor of 100. Our process was electroplating rather than vacuum deposition. In sequential plating of In over $\mathrm{Ag}$, the immediate formation of $\mathrm{AgIn}_{2}$ resulted from the high diffusion coefficient. As illustrated in Fig. 2, to grow $\mathrm{AgIn}$, near the surface, the $\mathrm{Ag}$ atoms have to diffuse through the 5- $\mu \mathrm{m}$-thick $\mathrm{AgIn}_{2}$ layer already grown to meet the In atoms. Alternatively, the In atoms may diffuse through the $\mathrm{AgIn}_{2}$ layer and arrive at the $\mathrm{AgIn}_{2}-\mathrm{Ag}$ interface to react with $\mathrm{Ag}$ atoms. At present, there is insufficient experimental data to determine which diffusion path dominates.

This study clearly shows that $\mathrm{AgIn}_{2}$ grows with time at room temperature due to rapid chemical reactions between the electroplated In and Ag layers. The formation of $\mathrm{AgIn}_{2}$ does affect the reflow temperature and wetting action during the bonding 
processes. In our previous project, high-temperature $\left(850^{\circ} \mathrm{C}\right)$ joints were produced at a low bonding temperature $\left(205^{\circ} \mathrm{C}\right)$ using sequential electroplated $\mathrm{Ag} / \mathrm{In} / \mathrm{Ag}$ layers. ${ }^{13} \mathrm{The} \mathrm{Ag} / \mathrm{In} / \mathrm{Ag}$ structure turns into $\mathrm{AgIn}_{2}$ before the bonding. Pure indium melts and turns entirely into a molten phase at $156^{\circ} \mathrm{C}$. $\mathrm{AgIn}_{2}$ decomposes at $166^{\circ} \mathrm{C}$ and turns into a mixture of a molten phase $(\mathrm{L})$ and $\mathrm{Ag}_{2}$ In $\left(\gamma\right.$ phase) grains. ${ }^{8}$ The wetting action of $\mathrm{AgIn}$, thus, is not as thorough as that of pure In. On the other hand, the existence of a $\mathrm{AgIn}_{2}$ layer provides the possibility of soldering without flux because the samples are protected against oxidation during storage by an outer $\mathrm{AgIn}_{2}$ layer.

\section{CONCLUSIONS}

We have studied the nucleation and growth mechanism of In clusters on a thick Ag layer using sequential electroplating in a sulfamate indium plating bath. During the plating process, In and Ag atoms continue to react to form $\mathrm{AgIn}_{2}$ intermetallic compounds at room temperature. It was surprising to find that the $\mathrm{AgIn}$ layer, as thick as $5 \mu \mathrm{m}$, can be formed after the sample had been made for 1 day. The AgIn ${ }_{2}$ layer continued to grow until all In atoms reacted with $\mathrm{Ag}$ atoms. This implies that $\mathrm{Ag}$ atoms can detach from the Ag layer and diffuse through the $\mathrm{AgIn}_{2}$ layer to meet the indium atoms on the surface. Another possibility is that the indium atoms diffuse through $\mathrm{AgIn}_{2}$ to meet the $\mathrm{Ag}$ atoms at the $\mathrm{AgIn}_{2}$-Ag interface. At present, we do not have experimental data to determine which diffusion path dominates. We believe that this In-Ag chemical reaction study could offer the electronics packaging community valuable information when dealing with substrates that are plated with $\mathrm{In} / \mathrm{Ag}$ structures.

\section{OPEN ACCESS}

This article is distributed under the terms of the Creative Commons Attribution Noncommercial License which permits any noncommercial use, distribution, and reproduction in any medium, provided the original author(s) and source are credited.

\section{REFERENCES}

1. http://www.yutopian.com/Yuan/prop/In.html.

2. S. Choe, W.W. So, and C.C. Lee, Proc. IEEE Electron. Compon. Technol. Conf. (2000), p. 114.

3. C.C. Lee, C.Y. Wang, and G. Matijasevic, IEEE Trans. Compon. Hybr. Manuf. Technol. 16, 311 (1993). doi:10.1109/ 33.232058.

4. Y.-C. Chen, W.W. So, and C.C. Lee, IEEE Trans. Compon. Packag. Manuf. Technol. 20, 46 (1997). doi:10.1109/95.558543.

5. C.C. Lee and W.W. So, Thin Solid Films 336, 196 (2000). doi:10.1016/S0040-6090(00)00727-6.

6. K.-M. Chu, J.-H. Choi, J.-S. Lee, H.S. Cho, S.-O. Park, H.-H. Park, and D.Y. Jeon, IEEE Trans. Adv. Packag. 29, 409 (2006). doi:10.1109/TADVP.2006.875417.

7. P.T. Vianco, J.A. Rejent, A.F. Fossum, and M.K. Neilsen, J. Mater. Sci.: Mater. Electron. 18, 93 (2007). doi:10.1007/ s10854-006-9013-7.

8. H. Okamoto and T.B. Massalski, Binary Alloy Phase Diagrams (Metal Park, OH: ASM International, 1990), pp. 381-383.

9. B.D. Cullity, Elements of $X$-ray Diffraction, 2nd ed. (Addison Wesley, 1978), p. 513.

10. http://henke.lbl.gov/optical_constants/atten2.html.

11. R. Roy and S.K. Ken, Thin Solid Films 197, 303 (1991). doi:10.1016/0040-6090(91)90241-O.

12. V. Simic and Z. Marinkovic, Thin Solid Films 61, 149 (1979). doi:10.1016/0040-6090(79)90457-7.

13. J.S. Kim, P.J. Wang, and C.C. Lee, IEEE Trans. Compon. Packag. Technol. 31, 782 (2008). doi:10.1109/TCAPT.2008. 2001195. 